PONTIFÍCIA UNIVERSIDADE CATÓLICA DO RIO DE JANEIRO

\title{
Tecnologia de Informação em Micro e Pequenas Empresas: Estudo de Caso
}

Wilbert Medeiros Carvalho de Brito Nogueira

Trabalho de Conclusão de Curso

Centro de CIÊnCIAS SOCIAIS - CCS

Departamento de AdMINISTRAÇÃo

Graduação em Administração de Empresas 
Wilbert Medeiros Carvalho de Brito Nogueira

Tecnologia de Informação em Micro e Pequenas Empresas:

Estudo de Caso

Trabalho de Conclusão de Curso

Trabalho de Conclusão de Curso, apresentado ao programa de graduação em Administração da PUC-Rio como requisito parcial para a obtenção do titulo de graduação em Administração.

Orientador: Edmundo Eutrópio

Rio de Janeiro, Novembro de 2015. 
"A inovação sempre significa um risco. Mas ir ao supermercado de carro para comprar pão também é arriscado. Qualquer atividade econômica é de alto risco e não inovar é muito mais arriscado do que construir o futuro." (Peter Drucker) 


\section{Agradecimentos}

Meus sinceros e eternos agradecimentos:

Ao meu pai, Nuno José de Brito Nogueira, minha mãe, Denise Medeiros de Carvalho e meu irmão, Nuno Guilherme Carvalho de Brito Nogueira, por tudo que fizeram por mim. Até hoje, sempre fui conduzido e educado da melhor forma possível e sempre me apoiaram em todas as minhas escolhas, ajudando a me tornar um profissional melhor e principalmente uma pessoa íntegra e honrosa, fruto do exemplo que sempre tive em casa. Amo vocês.

Ao meu orientador, Edmundo Eutrópio Coelho de Souza, no qual tive a sorte de ser orientado, sempre bastante atencioso e um exemplo de profissional e mestre. Muito obrigado pela paciência e ensinamentos.

A Pontifícia Universidade Católica, por ser essa faculdade maravilhosa, que proporciona oportunidade a todos, por onde passei os melhores anos da minha vida e pela qual tenho orgulho de ter feito parte.

E a todos os meus amigos, construídos na PUC e na vida. 


\section{Resumo}

Nogueira, Wilbert Carvalho. Eutrópio, Edmundo C. de. Automação de Micro e Pequenas Empresas. Rio de Janeiro, 2015. Número de páginas, 34. Relatório Final de Estágio Supervisionado II - Departamento de Administração. Pontifícia Universidade Católica do Rio de Janeiro.

Este trabalho busca estimular os pequenos empresários quanto a automação de seus negócios. Foram analisadas as percepções em relação à tecnologia e os motivos que possam dificultar a implementação. Como embasamento, foi utilizado um método qualitativo, através de pesquisa de estudo de caso e entrevistas presenciais. Dessa forma, se propõe o desenvolvimento de alternativas que estimulem os empresários ao crescimento e se tornar cada vez menos operacionais e mais estratégico.

PALAVRAS-CHAVE: Negócio; competitividade; software, tecnologia, organização, Impacto das inovações, estratégia.

\section{Abstract}

Nogueira, Wilbert Carvalho. Souza, Edmundo Eutrópio. Automation micro enterprises. Rio de Janeiro, 2015. Number of pages, 34. Final Report of Supervised Internship II - Department of Administration. Pontifical Catholic University of Rio de Janeiro.

This Study aims to encourage small business owners as the automation of their business. Perceptions about technology and the reasons that could hinder implementation were analyzed. As a support, we used the face interviews and study as case research method. Thus it, is proposed to develop alternatives that encourage business growth and become less operational and strategic.

KEYWORDS: Business, competitiveness, software, Technology, organization, innovation of impact, Strategic. 


\section{Sumário}

1 O tema e o problema de estudo 1

1.1. Introdução ao tema e ao problema do estudo 1

1.2. Objetivo do estudo 2

1.3. Objetivos intermediários do estudo 2

1.4. Delimitação e foco do estudo 3

1.5. Justificativa e relevância do estudo 3

2 Referencial Teórico 4

2.1. Micro e Pequenas Empresas (MPE's) 4

2.1.1. Inovação e competitividade 8

2.2. Sistemas de Gestão 11

2.2.1. Ferramentas Corporativas 12

2.2.2. Automação MPEs 15

2.3. Abordagem e mudança organizacional nas microempresas 16

3 Metodologia 19

3.1. Tipos de Pesquisa 19

3.1.1. Quanto aos fins 19

3.1.2. Quanto aos meios 20

3.2. Fontes, Instrumentos e procedimentos para coleta de dados 20

3.3. Tratamento e Análises dos dados 22

3.4. Limitações do Método 22

4 Apresentação e Análise de Resultados 23

4.1. Sobre o caso Empresa X 23

4.2. Análise dos dados $\quad 27$

5 Conclusão e recomendações para novos estudos 32

6 Referências Bibliográficas $\quad 34$ 


\section{Lista de Figuras}

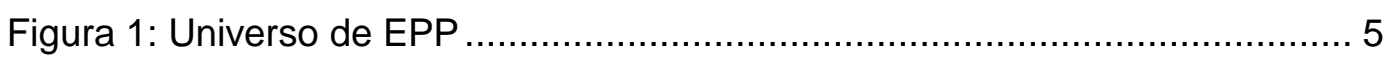

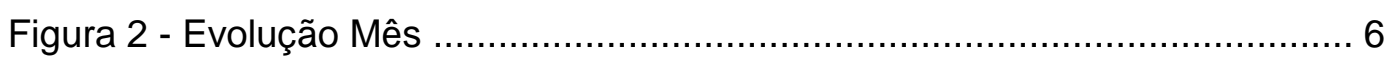

Figura 3 - EPP por setores ................................................................. 8

Figura 4 - Sistema MRP ......................................................................... 14

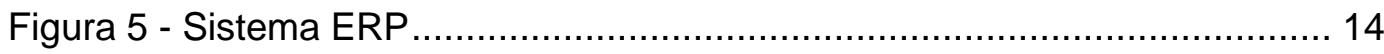

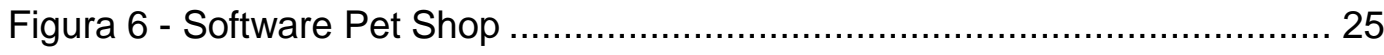

Figura 7 - Funções Software ................................................................ 26

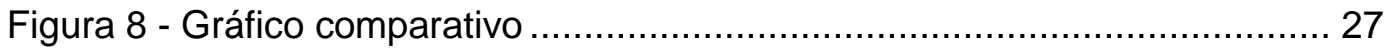

\section{Lista de Tabelas}

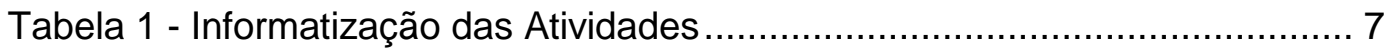

Tabela 2 - Ações para automação bem-sucedida ............................................. 29 


\section{0 tema e o problema de estudo}

\subsection{Introdução ao tema e ao problema do estudo}

As constantes mudanças na economia, variáveis políticas e socioeconômicas, fazem com que as pequenas e médias empresas tenham um desafio imenso para se destacarem no mercado perante as demais. Desta forma, as atividades de gestão e planejamento que antecedem a abertura de um negócio são primordiais para o sucesso e futuro financeiro desta pequena empresa. É muito importante estar sempre em equilíbrio em relação ao planejamento. Dimensionar recursos como capital, insumos, funcionários, conhecimento do mercado e atitude empreendedora são alguns dos passos importantes para atingir esse equilíbrio.

Pensando em Brasil, precisamos destacar a importância que essas pequenas empresas tem na questão financeira, social e política, de acordo com Luiz Barretto, Diretor-Presidente do Sebrae Nacional, as micro e pequenas empresas são as principais geradoras de riqueza no comércio no Brasil (53,4\% do PIB), tendo também uma participação significativa no PIB da Indústria $(22,5 \%)$ e mais de um terço da produção nacional do setor de serviços $(36,3 \%)$.

Dessa forma, percebemos a força que as MPEs (Micro e pequenas empresas) têm no mercado e principalmente na economia do Brasil, mostrando a importância de incentivarmos e qualificarmos 0 pequeno e microempreendedor, preparando o para uma jornada de desafios e proporcionando oportunidade de crescimento de sua empresa.

Segundo pesquisa SEBRAE (2011) a taxa de mortalidade das pequenas empresas está relacionada não só ao constante aumento das taxas tributárias e sim a falta de capital de giro, entendimento do business e concorrência forte, principalmente devido ao mercado informal. Diante disso, a automação de processos é a melhor forma de controle de atividades e controle financeiro do negócio.

Por definição, automação ou automatização é o sistema pelo qual os mecanismos controlam o seu próprio funcionamento, com a mínima interferência humana. 
Com o crescimento do mercado e principalmente da concorrência, fica claro a importância do pequeno empresário em aprimorar cada vez mais. Torna se primordial que possua consigo ferramentas de gestão tanto de capital, quanto de insumos e mão de obra. De forma, que este empresário consiga aprofundar seu pensamento no business e não ficar preso somente à atividade operacional.

Trazendo para o lado prático do negócio, a ideia é pensar e começar a desenhar uma estratégia de forma inversa. Devemos entender que quando o empresário está focado apenas no operacional do negócio, o mesmo tende a comprometer seu tempo "apagando incêndio" ao invés de desenvolver a sua pequena empresa para o crescimento próspero e contínuo.

Visto a importância da gestão operacional do negócio e da necessidade de automação para desenvolvimento das empresas, este estudo tem como objetivo responder o seguinte questionamento: Como podemos estimular a automação em micro e pequenos negócios?

\subsection{Objetivo do estudo}

Este trabalho tem como objetivo principal exemplificar e propor estratégias que estimulem uma maior automação dos pequenos negócios no Rio de Janeiro. Além disso, demonstrar o quanto a tecnologia da informação pode agregar valor à empresa, através de otimização de processos e redução de custos.

\subsection{Objetivos intermediários do estudo}

- Entender a percepção dos pequenos empresários em relação à importância estratégica da tecnologia da informação;

- Identificar os motivos que dificultam a automação em pequenos negócios, mesmo esse sendo um importante fator de crescimento;

- Recomendar a adoção de ferramentas de TI, de forma a estimular a automação por parte dos pequenos empresários. 


\subsection{Delimitação e foco do estudo}

O estudo tem como foco entender o posicionamento de pequenas e microempresas do estado do Rio de Janeiro perante a tecnologia de informação e a partir disso, propor a adoção de práticas de automação, partindo de um estudo de caso em uma PME.

Este trabalho visa abordar hábitos, preferências e comportamento de microempresas diante de soluções tecnológicas existentes no mercado, independente do ramo de atividade.

\subsection{Justificativa e relevância do estudo}

O estudo se faz necessário para melhorar a vida do pequeno empresário, proporcionando um crescimento e desenvolvimento da empresa de forma gradual permitindo uma estrutura muito mais enxuta para tomadas de decisões estratégicas.

A proposta do tema surgiu a partir da experiência profissional do autor deste estudo. Percebendo o constante crescimento do mercado de animais e produtos destinados a bichos de estimação, foi iniciada em 2010 a abertura de uma pequena empresa do ramo de Pet Shop no Rio de Janeiro - que iremos chamar de "Empresa X" - específicamente na região da Tijuca, com forte pensamento inovador, buscando a ampliação e captação de clientes de forma rápida, oferecendo um serviço de qualidade e personalizado.

Com a pouca experiência de mercado, o constante aumento de clientes, alto volume de trabalho operacional e pouco ou nenhum auxílio de ferramentas tecnológicas, a empresa cresceu de forma desestruturada, sem controles ou processos definidos. O que acabou se tornando um cíclo vicioso.

Citamos mais a frente, no capítulo estudo de caso, como a "empresa X" vem se comportando operacionalmente e o quão foi importante o processo de automação para saúde financeira da empresa. 


\section{Referencial Teórico}

Aborda se, neste Capítulo, os temas-chave para o processo de automação proposto por este estudo. São eles: Mercado, Sistemas de gestão e a Abordagem nas microempresas.

Os temas são tratados em partes. Iniciamos entendendo todo o vasto mercado de micro e pequenas empresas não automatizadas do estado do Rio de Janeiro e as inúmeras possibilidades de atuação. Posteriormente, abordamos as principais ferramentas de inovações do mercado e por fim, rastreamos as dificuldades e particularidades de implementação nas empresas.

\subsection{Micro e Pequenas Empresas (MPE's)}

O conceito de MPE's é um tanto quanto aleatório, não existe um acordo especifico para definir pequenas e microempresas, pois muitos autores e entidades adotam padrões e indicadores diferentes, como sugere Souza (2007) a definição de MPE's é ampla e diversificada, e varia de região, estado ou município.

Segundo o SEBRAE, que utiliza como segmentação os critérios da Lei Complementar 123/2006, também chamada de Lei Geral das Micro e Pequenas Empresas, os pequenos negócios são divididos da seguinte maneira:

- Micro empreendedor Individual - Faturamento anual de até $\mathrm{R} \$ 60$ Mil reais;

- Microempresa - Faturamento anual até $\mathrm{R} \$ 360 \mathrm{mil}$;

- Empresa de Pequeno Porte - Faturamento anual entre $\mathrm{R} \$ 360$ mil e $\mathrm{R} \$ 3,6$ milhões;

As EPP que apresentaram maior faturamento médio estão concentradas basicamente na indústria, estando incluídos a produção de bens intermediários e bens mais complexos. Nesse caso, necessita mão de obra mais especializada. O número de empresas enquadradas nesses quesitos é deveras pequeno. De maneira geral, as EPP estão concentradas na região Sudeste $(51,5 \%)$, mais precisamente no estado de São Paulo (30\%), cuja capital congrega mais de $10 \%$ das EPP brasileiras. 
Segundo a base de dados utilizada, em 2009 existiam 438.513 empresas de pequeno porte, assim distribuídas de acordo com a unidade da Federação e região:

\begin{tabular}{|c|c|c|}
\hline UF & Número & $\mathrm{x}$ \\
\hline $\mathrm{AC}$ & 534 & $0,12 \%$ \\
\hline AL & 2.416 & $0,55 \%$ \\
\hline AM & 2.332 & $0,53 \%$ \\
\hline AP & 451 & $0,10 \%$ \\
\hline $\mathrm{BA}$ & 18.451 & $4,21 \%$ \\
\hline $\mathrm{CE}$ & 9.750 & $2,22 \%$ \\
\hline DF & 7.998 & $1,82 \%$ \\
\hline ES & 11.109 & $2,53 \%$ \\
\hline GO & 16.102 & $3,67 \%$ \\
\hline MA & 4.040 & $0,92 \%$ \\
\hline MG & 45.342 & $10,34 \%$ \\
\hline MS & 4.920 & $1,12 \%$ \\
\hline MT & 7.031 & $1,60 \%$ \\
\hline PA & 5.561 & $1,27 \%$ \\
\hline PB & 4.395 & $1,00 \%$ \\
\hline PE & 9.120 & $2,08 \%$ \\
\hline PI & 2.548 & $0,58 \%$ \\
\hline PR & 37.864 & $8,63 \%$ \\
\hline RU & 36.910 & $8,42 \%$ \\
\hline RN & 4.128 & $0,94 \%$ \\
\hline RO & 3.222 & $0,73 \%$ \\
\hline RR & 530 & $0,12 \%$ \\
\hline RS & 39.893 & $9,10 \%$ \\
\hline sc & 26.757 & $6,10 \%$ \\
\hline SE & 2.345 & $0,53 \%$ \\
\hline SP & 132.501 & $30,22 \%$ \\
\hline TO & 2.263 & $0,52 \%$ \\
\hline TOTAL & 438.513 & \\
\hline
\end{tabular}

Figura 1: Universo de EPP

Fonte: SEBRAE

Como se pode observar, as EPP estão concentradas essencialmente no eixo Sul-Sudeste, que responde por mais de três quartos do universo total. Em números absolutos, o estado de São Paulo é o mais importante, com 132.501 pequenas empresas, cerca de $30 \%$ do total. Porém, segundo pesquisa SEBRAE sobre a evolução de micro e Empresas de Pequeno Porte (EPP), temos 
destaque para o Rio de Janeiro com um dos maiores números em crescimento de faturamento médio.

Abaixo, podemos observar a evolução de 2009 a 2012 em relação a faturamento médio de $\mathrm{ME}$ em reais:

954.978,04

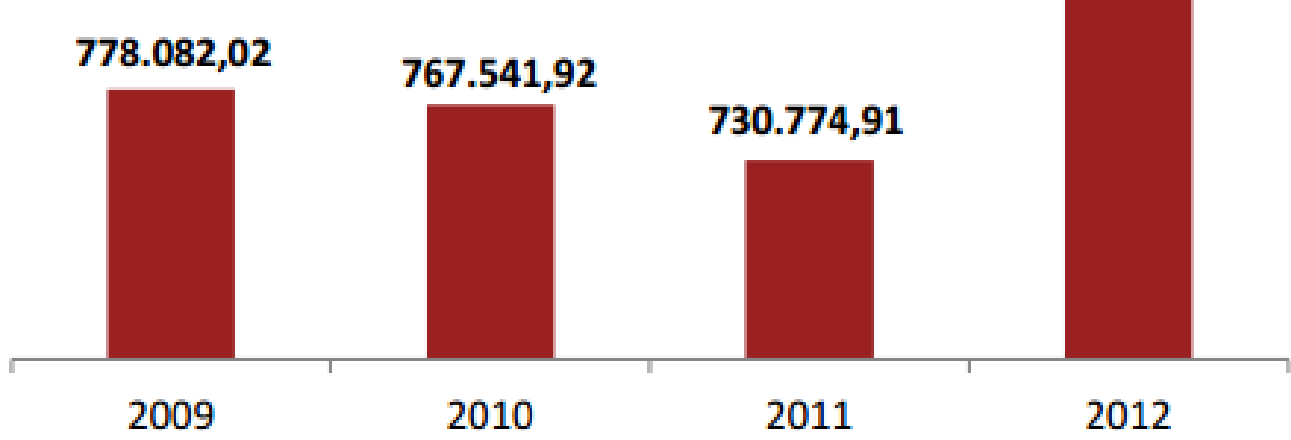

Figura 2 - Evolução Mês

Fonte: SEBRAE

Segundo Chiavenato (2005), "a atividade do administrador consiste em guiar e convergir as organizações rumo ao alcance dos objetivos. (...) 0 administrador alcança resultados através de sua organização e das pessoas que nela trabalham. Para tanto, planeja, organiza, dirige pessoas e controla recursos materiais, financeiros, informação e tecnologia visando o alcance de determinados objetivos."

Pensando dessa forma, a mudança tecnológica nas grandes empresas vem ocorrendo de forma acelerada, principalmente puxada pela necessidade de se diferenciar perante a concorrência e também como forma de reduzir seus custos operacionais com a automatização dos processos. Isso significa que a gestão tecnológica é absolutamente essencial para a estratégia global de negócios.

Essa estratégia executiva tem enorme impacto sobre a capacidade de uma organização de prestar serviços e/ou fornecer produtos, conquistar clientes, gerenciar as operações e, por fim, gerar lucro. Da mesma forma que as grandes empresas enxergam a constante necessidade de se reestruturar perante a tecnologia, se faz necessário o mesmo pensamento para administrador do 
pequeno negócio. O pequeno empreendedor tem que pensar em gerar valor ao seu cliente, gerando consequentemente lucro ao negócio, com o menor desgaste operacional possível.

Segundo pesquisa de Bedê (2003), há uma grande diferença na proporção de MPEs informatizadas. Em geral, as empresas menos informatizadas estão relacionadas a atividades mais tradicionais, ou seja, que possuem menos valor agregado e se utilizam de tecnologia mais convencional devido a inerência do negócio e apresentam maior quantidade de operações manuais. Por outro lado, as atividades que envolvem um dinamismo maior, que envolvem uma tecnologia mais sofisticada, possuem maior quantidade de produtos heterogêneos e consequentemente possuem maior valor agregado estão entre as mais informatizadas e automatizadas.

Abaixo um quadro com as atividades mais informatizadas e menos informatizadas, separadas por setor de atividades:

\begin{tabular}{|c|c|c|}
\hline Setor & | Atividades mais informatizadas & Atividades menos informatizadas \\
\hline Indústria & $\begin{array}{l}\text { Borracha e Plásticos } \\
\text { Máquinas e Equipamentos } \\
\text { Edição Gráfica } \\
\text { Construção Civil } \\
\text { (Edificações etc.) }\end{array}$ & $\begin{array}{l}\text { Couro e Calçados } \\
\text { Alimentos e Bebidas } \\
\text { Móveis e Diversos } \\
\text { Confeções } \\
\text { Metalurgia - não equipamentos } \\
\text { Têxtil }\end{array}$ \\
\hline Comércio & $\begin{array}{l}\text { Farmácia e Perfumaria } \\
\text { Autopeças } \\
\text { Materiais de Construção } \\
\text { Mercearias e Minimercados } \\
\text { Livrarias }\end{array}$ & $\begin{array}{l}\text { Comércio de bebidas } \\
\text { Bazares e varejo de diversos } \\
\text { Móveis e lluminação } \\
\text { Quitandas, Avícolas e Peixarias } \\
\text { Armarinhos } \\
\text { Oficinas mecânicas } \\
\text { Lava-rápidos etc. } \\
\text { Vestuário }\end{array}$ \\
\hline Serviços & $\begin{array}{l}\text { Serviços Ativs. Informática } \\
\text { Aluguel de veículos } \\
\text { Máquinas e objetos pessoais } \\
\text { Imobiliárias } \\
\text { Às Empresas (de contab., arquit. } \\
\text { E Eng., copiadoras) } \\
\text { Agências de viagem } \\
\text { Recreação (Acad. Ginástica, } \\
\text { natação etc.) }\end{array}$ & $\begin{array}{l}\text { Servs. de Alim. (p.ex, lanchonetes) } \\
\text { Servs. Pessoais (higiene e beleza, } \\
\text { lavanderias) } \\
\text { Servs. de Transporte }\end{array}$ \\
\hline
\end{tabular}

Tabela 1 - Informatização das Atividades

Fonte: Informatização das MPEs Paulistas 


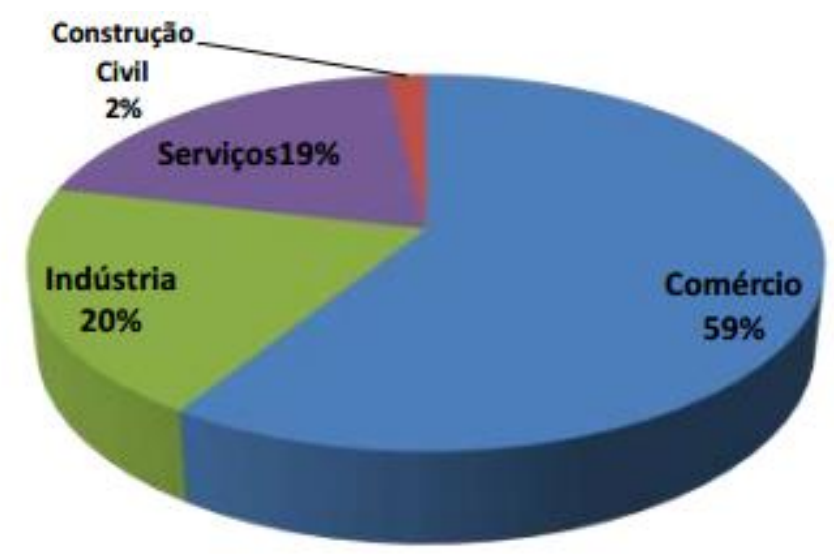

\section{Figura 3 - EPP por setores}

Fonte: SEBRAE

Veremos nos próximos capítulos como o pequeno empresário pode enxergar o valor da inovação para o seu negócio e a aplicabilidade dela em sua empresa. Entendendo que o mercado está muito mais competitivo que no passado e as cargas tributárias estão cada vez mais pesadas, podemos perceber que essa mudança de cultura organizacional, bem mais racional e tecnológica, veio para ajudar esse pequeno administrador.

\subsubsection{Inovação e competitividade}

"O segundo princípio fundamental de administração mais avançada é: alavancar tecnologia e competência para impulsionar a inovação sustentável e capturar vantagem competitiva. $O$ modelo de geração mais avançada requer a construção do que chamamos plataformas de tecnologia e competência, compostas por uma poderosa mistura talentos humanos, competências e tecnologias de ponta, que podem fazer acelerar o crescimento e aperfeiçoar o desempenho." (Jonash, 2001)

Hall (1984), afirma que uma tipologia das organizações genericamente aceita é inexistente, apesar de um consenso geral dos administradores sobre a necessidade desesperadora de uma boa classificação tipológica. Ou seja, apesar da complexidade claramente vista a respeito dos tipos de organizações, se fazia necessário uma classificação global adequada, levando em conta as condições externas, o espectro total das ações e interações na organização e ainda o resultado dos comportamentos organizacionais.

Tachizawa (2006) classifica de forma interessante as organizações com base na tipologia, usando a referida classificação como possibilidade de 
determinar sua orientação. Com base em uma amostra extraída da publicação Melhores e Maiores da revista Exame seguem abaixo as classificações das empresas por Setor Econômico:

a) Setor de empresas competitivas;

b) Setor econômico concentrado;

c) Setor de empresas diferenciadas;

d) Setor econômico misto;

e) Setor econômico semiconcentrado;

f) Setor de serviços financeiros;

g) Setor de serviços especializados; e

h) Setor de serviços públicos;

Vamos nos prender apenas a classificação de empresas competitivas, onde podemos avaliar este setor da economia que possibilita que empresas com maior produtividade ganhem participação de market share em detrimento das menos eficazes. Este ramo de negócios é totalmente afetado por variáveis ambientais, normalmente é favorecido pelo aumento do poder aquisitivo do consumidor, ampliações das linhas de créditos, redução das alíquotas para materiais importados, juros e melhora na estabilidade de empregos.

As empresas enquadradas no setor de empresas competitivas, de acordo com sua tipologia, como por exemplo, o comércio varejista como um todo, se caracteriza pelo alto giro de seus ativos. Essas empresas possuem como diferencial para os demais setores:
a) O fato de não existir barreiras de entradas para novas empresas;
b) Nenhuma empresa tem monopólio do mercado;
c) Grande número de pequenas empresas no mercado, com custos elevados e menor taxa de lucratividade;
d) Forte poder de barganha dos fornecedores e intermediários;
e) Baixo nível de desenvolvimento tecnológico;
f) Alta rotatividade de serviços e produtos ofertados;
g) Competição via preços

Para garantir a sobrevivência perante esse setor altamente competitivo às empresas precisam constantemente buscar formas de se adaptar a novas 
realidades e principalmente inovar, pois sem essas ações que buscam a alta produtividade, dificilmente conseguirão se destacar perante as demais.

Segundo definição de Edquist, um sistema de inovação é o que determina os processos e as próprias inovações. Os processos de inovação, segundo ele, se desenvolvem ao longo do tempo e são influenciados por muitos fatores. Razão pela qual podem ser caracterizados como revolucionários. Para ele, os sistemas de inovações não deveriam chegar a um equilíbrio e devem estar em constante movimento, ou seja, Edquist considera que jamais devemos falar que o sistema utilizado é ótimo ou ideal para a sua empresa em matéria de inovação e entende que essa deve ser uma busca constante de todos os empresários.

No âmbito político Charles Edquist, cita a importância de o governo estimular tais processos de inovação, pois ele vai muito além da simples melhora da produtividade das pequenas empresas e entra na questão de geração de valor a economia, trazendo a tona o cenário macroeconômico e a negligência das políticas de inovação no Brasil. "As políticas de inovação podem ser de caráter econômico, militar, ambiental, social, relacionado a saúde ou a qualquer coisa que represente um problema social. Quando são econômicos, esses objetivos dizem respeito ao crescimento, à produtividade, ao emprego e à competitividade. No entanto, eles devem ser trazidos em objetivos diretos quando se trata de inovação. Isso não é feito quase nunca, porque os políticos e os formuladores de políticas estão mais interessados nos resultados das inovações do que propriamente no apoio a elas", disse Charles Edquist.

Para Arbix, o principal gargalo para que o Brasil se torne uma força global em diversas áreas é justamente a educação e estimulo a inovação. O autor cita uma evolução versus as políticas adotadas dos anos 40 aos anos 80 , onde a tecnologia era vista como um subproduto natural do crescimento econômico. Assim como Edquist, Arbix defende a mudança cultural e comportamental da esfera pública, entendendo que só assim conseguiremos reduzir gaps importantes na área de tecnologia e inovação, visto que dependência tecnológica, sustentabilidade e crescimento estão totalmente relacionados.

Em relação as MPEs, Arbix considera a posição do Sebrae cada vez mais estratégica, visto a vulnerabilidade das micro e pequenas empresas versus as empresas de grande porte. Basta observar a abundância do mercado interno, recursos naturais e oportunidades de crescimento, principalmente através da geração de crédito ao pequeno empresário.

Quando se fala em inovação, nos vêm à cabeça, novas ideias, processos, e novas soluções para problemas antigos e novos. Um empresário inovador 
consegue vencer a crise e o mercado altamente competitivo através de sua visão mais estratégica, visão essa que se distancie da atividade puramente operacional. Mas entendemos que a implementação de processos e ferramentas inovadoras historicamente sempre enfrentou dificuldade. Apesar disso, com o apoio de órgãos financiadores (como o Finep) e orientadores (como Sebrae), micro e pequenos empresários tem a oportunidade de driblar as dificuldades e atingir o sucesso esperado.

\subsection{Sistemas de Gestão}

As mudanças tecnológicas nas grandes empresas vêm ocorrendo de forma acelerada, principalmente puxada pela necessidade de se diferenciar perante a concorrência e também como forma de reduzir seus custos operacionais, com a automatização dos processos. Isso significa que a gestão tecnológica é absolutamente essencial para a estratégia global de negócios. Essa estratégia executiva tem enorme impacto sobre a capacidade de uma organização de prestar serviços e/ou fornecer produtos, conquistar clientes, gerenciar as operações e, por fim, gerar lucro. Da mesma maneira que as grandes empresas enxergam a constante necessidade de se reestruturar perante a tecnologia, se faz necessário o mesmo pensamento para empresas de pequeno porte. O pequeno empreendedor tem que pensar em gerar valor ao seu cliente, gerando consequentemente lucro ao negócio, com o menor desgaste operacional possível.

Segundo Tachizawa e Scaico, "os sistemas, tecnologias de informação e processos inerentes à organização somente fazem sentido se contribuírem, direta ou indiretamente, à implementação das estratégias definidas para a empresa." Sobre os processos de caráter tecnológico, o pequeno empresário deve observar:

a) Objetivos: identificar os processos mais críticos à estratégia e determinar todos os objetivos do processo.

b) Projeto: entender os impactos de interface no ambiente interno e externo a organização e adaptar da melhor forma os processos já existentes ao novo.

c) Gerenciamento: estipular objetivos no start do processo, monitorar e aperfeiçoar constantemente o desempenho do novo processo. 
Ainda segundo Tachizawa e Scaico, "as organizações pertencentes ao setor de empresas competitivas, em condições normais, poderiam adotar tecnologias de informação aplicadas à gestão dos estoques, automação comercial e software financeiro de fluxo de caixa".

A mesma estratégia tem que ser adotada para as pessoas, ou seja, juntamente com os aspectos sistêmicos, processos e configuração organizacional por parte da tecnologia é necessário o mesmo suporte às estratégias profissionais e pessoais do trabalhador:

a) Objetivos: identificar os processos mais críticos ao sucesso do processo

b) Projeto: projetar e organizar a nova organização e atividade de modo que os funcionários consigam atingir os objetivos de forma eficiente e eficaz

c) Gerenciamento: Especificações claras, capacitar e treinar os funcionários para a nova ferramenta.

"Tanto no setor misto, serviços financeiros e empresas competitivas, as organizações, normalmente, têm possibilidade de implementar políticas de gestão de pessoas com ênfase em salários e benefícios, contemplando de forma privilegiada as relações trabalhistas em sua esfera de atuação." - Tachizawa e Scaico

\subsubsection{Ferramentas Corporativas}

Existem diversos tipos de ferramentas para gerir as operações de uma empresa. Como uma grande aliada do empresário, a tecnologia vem cada vez mais tendo maior importância quando se fala em "sobrevivência" das empresas e com ela é possível diminuir as tarefas e otimizar o tempo de trabalho. Ou seja, cada vez mais a tecnologia entra no caminho do pequeno e médio empresário e se transforma como excelente oportunidade de crescimento, oferecendo uma infinidade de opções para comunicação entre o cliente e a empresa.

A principal ferramenta de automação das grandes empresas são os sistemas chamados de MRP. O material requirement planning, pode ser traduzido por planejamento das necessidades de materiais. Basicamente, é um sistema lógico de calculo que converte a previsão de demanda em programação 
da necessidade de seus componentes, muito usado para controlar linha de produção versus necessidade, por exemplo. A partir do conhecimento de todos os componentes de um determinado produto e os tempos de obtenção de cada um deles, podemos, com base na visão de futuro das necessidades, calcular o quanto e quando se deve obter de cada item, de forma que não haja falta e nem sobra no suprimento das necessidades da produção, mas sem considerar a capacidade de recurso para execução do plano. Esses sistemas são módulos de pacotes de software de sistemas de informação que auxiliam na tomada de decisão gerencial, mais conhecidos como ERP (Enterprise Resources Planning).

Segundo Carmelito, os ERPs são pacotes padronizados e geralmente provenientes de empresas estrangeiras. Alguns nomes comerciais de sistemas de informações mais conhecidos são; SAP/R-3, BAAN4, Oracle Applications, BPCS, Peoplesoft, JDEdwards e MFG/Pro.

O ERPs possuem alto custo de implementação e do próprio pacote em si e a forma como é padronizado muitas vezes não correspondem com a real necessidade da empresa. O não atendimento das necessidades por estes pacotes faz com que as empresas optem pela customização que encarece ainda mais o sistema, ou pelo próprio desenvolvimento de sistemas paralelos que descaracteriza o modelo de integração dos sistemas. Além disso, no processo de implementação de um sistema ERP, principalmente no que se refere ao planejamento, os usuários necessitam estar muito preparados e treinados para operar a ferramenta, sendo necessário um conhecimento muito específico da dinâmica e do conceito utilizado no software, o que requer muito tempo para implementação. Caso contrário, a ferramenta torna se uma simples listagem de estoque.

Quando falamos em automação das MPEs, temos que pensar em ferramentas com custos baixos, alto poder de personalização e dinâmica para operacionalizar. Isso significa que torna se inviável a utilização de MRPs ou ERPs nas micro e pequenas empresas.

Abaixo figuras de como se comportam as ferramentas dentro das grandes organizações e exemplos de fluxos conceituais: 


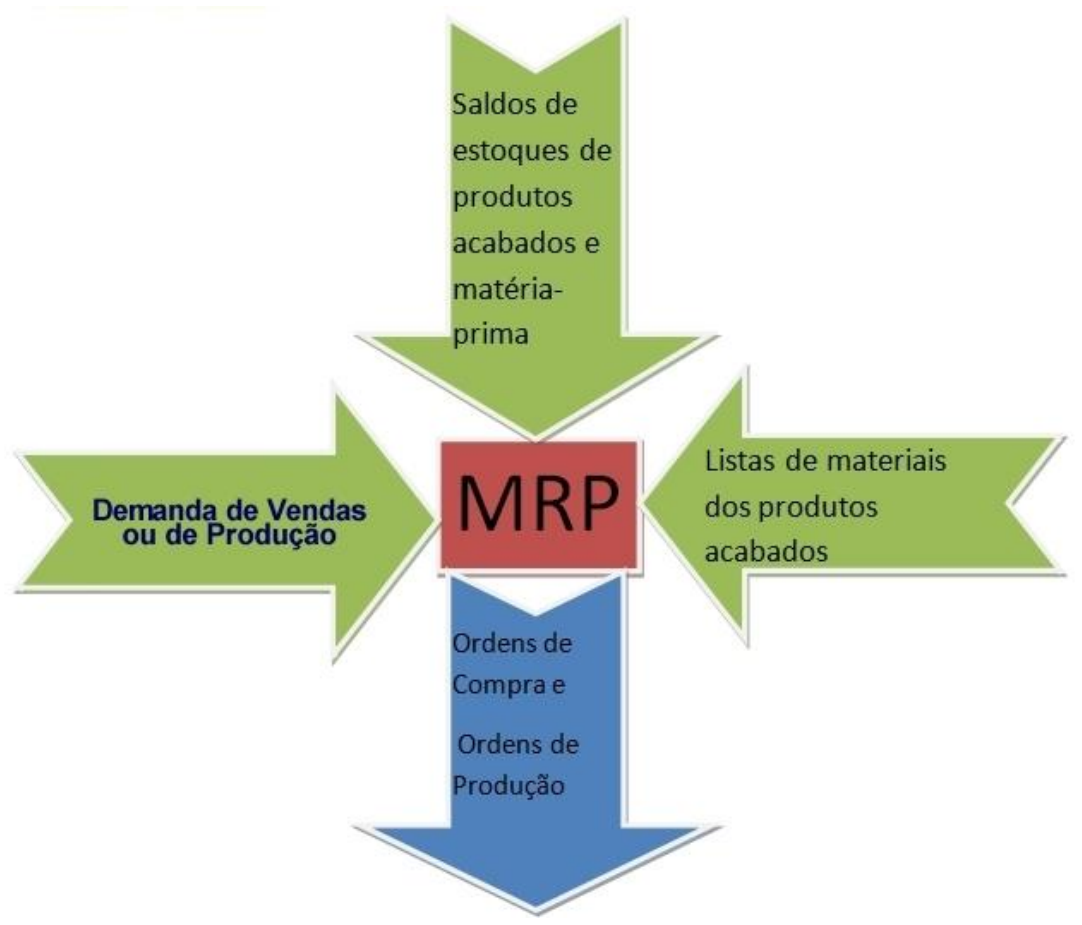

Figura 4 - Sistema MRP

Fonte: www.gestaoindustrial.com/

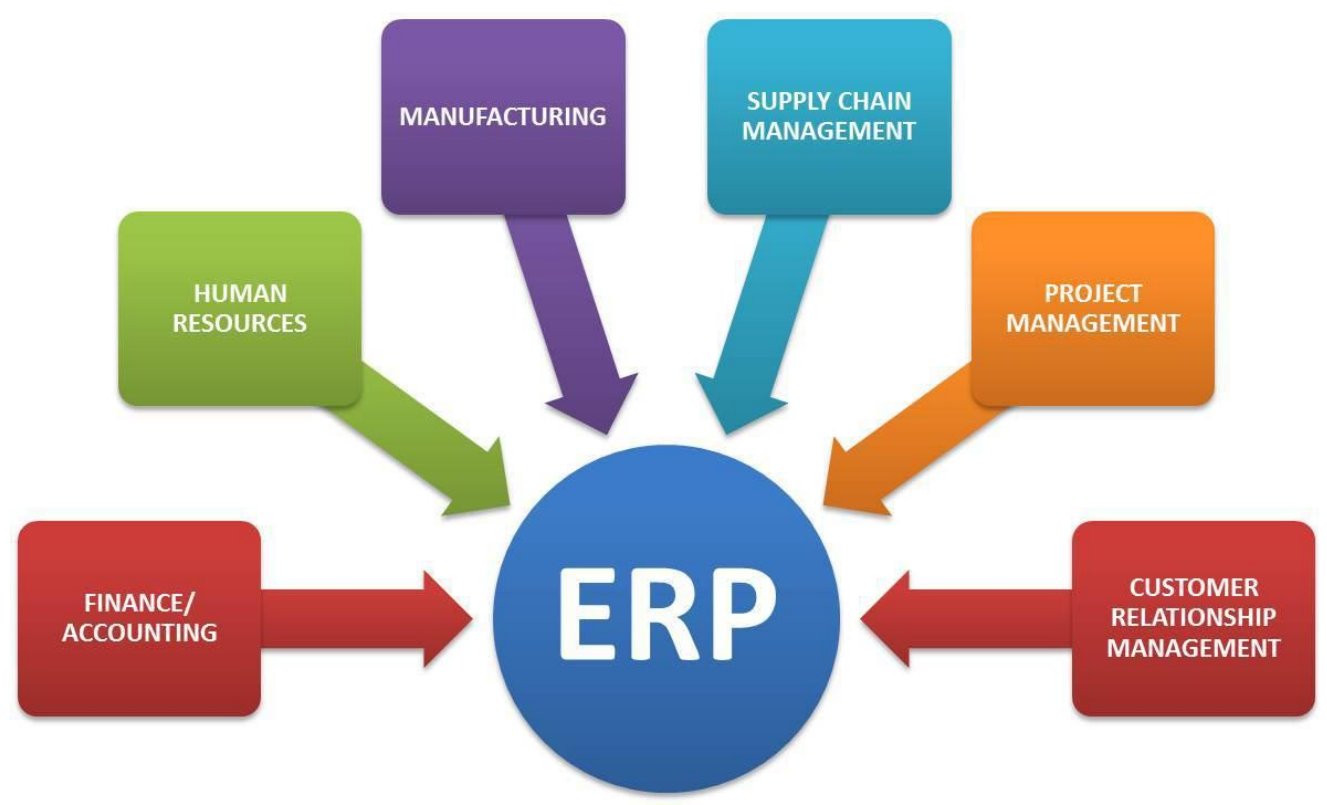

Figura 5 - Sistema ERP

Fonte: www.gestaoindustrial.com/ 
Segundo Tachizawa e Scaico, as mudanças tecnológicas realizadas agora afetarão de modo significativo o futuro dos negócios da empresa em um horizonte de três, cinco ou mais anos adiante. A produtividade da informática no ambiente de trabalho deve ser medida em termos do impacto sobre as atividades de negócios e da satisfação dos clientes, a partir das decisões implementadas pela empresa. É necessário estabelecer reflexões e avaliar os diferentes caminhos que a organização irá trilhar a partir das tecnologias de informação e os modos de reconfiguração escolhidos. Sempre levar em consideração o grau de contribuição que possam dar a obtenção de melhores resultados corporativos, ou mesmo de melhoria da produtividade da empresa, afirmou Tachizawa e Scaico, direcionando as grandes organizações, mas facilmente e idealmente aplicado as micro e pequenas empresas.

\subsubsection{Automação MPEs}

Neste capítulo é interessante mostrar que qualquer empresa se utiliza de algum tipo de ferramenta tecnológica para controlar sua operação. É um fato que por mais abrangente que seja sua estratégia de inovação e processos, tudo se resume a execução. Porém, o que acontece em muitas micro e pequenas empresas é que o papel estratégico torna se quase inexistente quando o microempresário entra em uma rotina de trabalho. Segundo Jonash (2001), nas empresas mais avançadas as plataformas de automação são estruturas informais, alianças livres de pessoas organizadas de qualquer maneira, em torno de áreas particulares de especialização. Ou seja, ao traçar uma estratégia de geração mais rebuscada, é preciso identificar e caracterizar esses sistemas de acordo com a percepção dos enfoques para sua empresa.

Jonash (2001) separa em quatro formas diferentes as estratégias de controlar gerencialmente, investir e alinhar seu negócio:

- Conhecimento e aprendizado - requer menos investimento, estando ligado a exploração de áreas pouco conhecidas na empresa, sendo um interessante ponto de exploração à inovação.

- Excelência e construção de liderança - desenvolver tecnologia e inovar alguma área com base na necessidade de seu cliente. Exige grande comprometimento de recursos.

- Inovação e desenvolvimento - investimento pesado na inovação de novos produtos e ou serviços 
- Desempenho e crescimento do negócio - foca na especialidade da empresa e continua desenvolvendo produtos e serviços para ganhar share diante da concorrência.

Segundo o autor essas quatro plataformas são a essência da escolha estratégica mais avançada. Ou seja, o microempresário precisa decidir aonde focar sua estratégia para inovar e automatizar seus processos, visando não comprometer todos os seus recursos e assim desenvolvendo gradativamente a organização.

Existem diversas ferramentas de gestão de micro e pequenas empresas no mercado, que variam seu valor, de acordo com a amplitude oferecida pela ferramenta e pela tecnologia utilizada. Citamos como principal ferramenta, tanto pela eficiência, quanto pelo custo, os softwares de gestão. Essa tecnologia pode ser encontrada na nuvem, o que a torna ainda mais interessante. A gestão "na nuvem" é capaz de facilitar a portabilidade de arquivos e tornar simples a edição simultânea de um arquivo entre pessoas distantes geograficamente. Por não necessitarem de gastos elevados com servidores e licenças de softwares, são mais baratos do que os tradicionais, porém, a principal vantagem é a redução de custo operacional. Desenvolver e manter o sistema utilizado pesa menos no bolso do microempresário. Entre outras facilidades de utilizar a gestão "na nuvem", é o fato de as atualizações serem constantes sem que haja custos adicionais aos usuários.

\subsection{Abordagem e mudança organizacional nas microempresas}

As organizações que pretendem ser bens sucedidas terão que buscar a inovação como ponto crucial de seus negócios. Para Drucker (1980) as organizações devem buscar sistematicamente a inovação e abandonar 0 passado, utilizando uma atitude empreendedora. Utilizando inovações constantes a organização terá a grande vantagem de ter recursos humanos e capital para inovar dentro das atuais condições tecnológicas e de mercado.

Ainda Drucker (1986) a inovação é uma ferramenta específica dos empresários, o meio através da qual eles exploram a mudança como oportunidade para um negócio ou um serviço diferente. Enfatiza ainda que é necessário procurar deliberadamente as fontes de inovação, as mudanças e seus sintomas, que assinalam oportunidades para inovações bem-sucedidas. 
Falando dos impactos da implementação nas organizações é importante citar Lewin (1951). Este autor contribuiu para os estudos de mudança nas organizações, para o qual afirma que as organizações são sistemas dinâmicos que não conseguimos realmente compreender a menos que ocorra uma intervenção nessa dinâmica. Porém, essa intervenção não pode ser pautada no acaso, pois desse modo não será declarado a busca da eficiência. Outro ponto interessante é o termo resistência organizacional que foi cunhada por Lewin (1951). Segundo sua definição a resistência ocorreria quando um indivíduo ou um grupo tentasse impedir o sistema de atingir um novo patamar de equilíbrio. Essa ideia inicial de resistência organizacional foi a responsável por disseminar e implantar no campo das organizações tantos outros trabalhos, que pregaram a resistência como implicação direta da inércia organizacional, um dos fatores que explica a não implementação de processos de automação nas MPEs.

A partir de estudos de Lewin (1951), conseguimos entender a importância do contexto social da organização. Visto que, o principal objetivo desse trabalho é entender os anseios dos pequenos e micro empresários em relação a automação de suas empresas, se faz necessário melhorar a capacidade e habilidade de organizar e resolver problemas organizacionais fazendo com que os atores envolvidos compreendam a ligação existente entre a teoria e a prática.

Lewin (1951) propõe de forma interessante diferentes abordagens nas empresas. Entende que o processo de mudança deve ocorrer de forma gradual, respeitando basicamente três fases. A primeira, o que chama de descongelamento, implica a diminuição da força dos valores, atitudes ou comportamentos anteriores a partir da percepção de novas experiências ou informações que desafiam aqueles, traduzindo-se numa insatisfação com o estado atual da empresa e propostas de mudanças. Esta fase de descongelamento de certa forma gera a necessidade de mudança, motivando os profissionais a mudar, mas requer uma criação de segurança psicológica como forma de reduzir a resistência para alterar a situação presente. A segunda, envolve o desenvolvimento de novos valores, atitudes, comportamentos, dentro da cultura da empresa. Esta mudança é um processo sociocognitivo, afetivo e comportamental e não se verificará realmente se não existir motivação prévia das pessoas ou dos grupos para adquirir nova informação que permita ver a situação de um modo diferente. Por último e não menos importante, no qual Lewin chama de "o recongelamento", consiste na estabilização das mudanças efetuadas, as quais são integradas nos processos operacionais normais da empresa, devendo ser reforçadas e além de se tornar objeto de nova análise 
segundo a dinâmica da organização. Esta estabilização é necessária para evitar retrocessos à situação anterior à mudança e a sua duração varia de acordo com o impacto das mesmas na organização.

Basicamente, fechamos entendendo que a mudança no contexto organizacional engloba alterações fundamentais no comportamento humano, dos padrões de trabalho e nos valores em resposta a modificações ou antecipando alterações estratégicas, de recursos ou de tecnologia. Sendo o grande desafio não somente a mudança tecnológica, mas sim mudar pessoas e culturas organizacionais, renovando seus valores para ganhar vantagem competitiva. 


\section{Metodologia}

Para obtermos melhores resultados para um nicho do mercado de micro e pequenas empresas do Rio de Janeiro, a pesquisa qualitativa foi aplicada, para substituir as informações estatísticas e teóricas que possuímos até o momento. A ideia foi captar dados psicológicos que são reprimidos ou não facilmente articulados, como atitudes, motivos pressupostos, muitas vezes internalizados pelos pequenos empresários, mostrando assim riscos e receios na implementação da tecnologia sugerida.

\subsection{Tipos de Pesquisa}

Foi adotada uma abordagem de pesquisa baseada em um estudo de caso real da "empresa X", sinalizado na introdução. Esta abordagem permitiu estudar e refletir sobre o fenômeno de automação das micro e pequenas empresas do Rio de Janeiro e entender os anseios dos empresários a respeito do processo.

Para a classificação da pesquisa, foi adotado como referencial o critério proposto por Vergara (2003), que expõe em relação a dois aspectos: quanto aos fins e quanto aos meios.

\subsubsection{Quanto aos fins}

Quanto aos fins, a pesquisa foi classificada como exploratória e descritiva. A escolha da pesquisa descritiva teve por objetivo descrever as características de uma população, de um fenômeno ou de uma experiência, através de um estudo de caso real, onde após a coleta de dados foi realizada uma análise das relações entre as variáveis, para uma posterior determinação dos efeitos resultantes em uma empresa. Exploratória, pois essa pesquisa se restringe por definir objetivos e buscar mais informações sobre o tema. 


\subsubsection{Quanto aos meios}

- Através de uma pesquisa Bibliográfica, sendo desenvolvida a partir de materiais publicados em livros, artigos, dissertações, teses e sites;

- Através de uma pesquisa Documental, ou seja, sobre forma de investigação, por meio de documentos, com o objetivo de descrever e comparar os costumes, comportamentos, diferenças e outras características, tanto da realidade presente, como do passado;

- Estudo de Caso, sob forma de estudo profundo do objeto, detalhando e analisando o problema com abordagem qualitativa.

\subsection{Fontes, Instrumentos e procedimentos para coleta de dados}

Foram pesquisados livros, revistas especializadas e sites específicos. A pesquisa documental coletou dados nas fontes internas da empresa estudada, sendo levantados as diretrizes e contexto da empresa através de documentos internos. Também foram coletados dados através de entrevistas individuais, com o objetivo de obter melhor qualidade dos dados referente aos aspectos da vida social. As entrevistas foram realizadas com base em um questionário préviamente elaborado, porém não ocorreu de forma sequencial. Tal procedimento foi escolhido, pois a coleta de dados fica mais precisa em uma conversa aonde não temos um ordenamento a ser seguido obrigatoriamente, podendo variar de acordo com a condução da entrevista e de acordo com a pessoa que está sendo investigada.

Para o tema proposto foi preparado um questionário para orientação na condução das perguntas e para que assim fosse garantida a abordagem geral de todo o tema. Antes de realizar a entrevista foi realizado com cada candidato uma breve introdução do tema e do caso da empresa $X$, onde os entrevistados tiveram a liberdade de falar a vontade, inclusive sobre assuntos correlacionados ao tema. Segue abaixo as perguntas desenvolvidas:

I. Sob a ótica de problemas e vantagens de automatização de processsos das grandes empresas, qual o seu posicionamento quanto ao aumento dos gastos em tecnologia e inovação das empresas globais? 
II. Seria possível gerir uma grande empresa hoje, sem o auxílio de ferramentas tecnológicas, como softwares, MRPs, ERPs ou boa base de TI? Para você, qual seria a principal dificuldade encontrada por essa empresa para implatação de tais tecnologias? Qual futuro você enxerga para essas empresas?

III. Entrando no âmbito dos nossos negócios de MPEs (Micro e pequenas empresas). Como você enxerga o cenário de crescimento para essas empresas sob a ótica da tecnologia e automação de processos e atividades diárias?

IV. Pensando em sua empresa, você possui algum tipo de software que proporcione um modelo mais automatizado dos processos e gestão de suas atividades? Se possui, quais? E quando passou a utilizá la?

V. Caso negativo, sem o auxilio de qualquer tipo de ferramenta tecnológica, você consegue gerir sua empresa sem ter problema com controle de estoque, pagamentos de fornecedores, fechamentos financeiros e atendimento ao cliente? Acha que um sistema iria proporcionar um ganho de produtividade operacional e abertura para um pensamento mais estratégico?

VI. Ao implementar esses softwares, chegou a fazer algum tipo de cotação? Qual variável levou em consideração para escolha do sistema atual? Quais os motivos que são primordias para escolha da tecnologia a ser utilizada?

VII. Percebeu algum tipo de diferença, seja na forma de condução de seu negócio, ou ganho financeiro? Percebeu algum valor agregado que justificou tal investimento? Quais foram as suas principais dificuldades na hora de implementar tais sistemas e tecnologias de automação?

VIII. Pretende investir em tecnologia nos próximos meses ou anos? Se sim, quanto está disposto a gastar? O que você espera desse novo investimento?

IX. Pensando no seu negócio hoje, considera que após a implementação do software em sua empresa você conseguiu perceber ganhos financeiros que compensaram o investimento na tecnologia? Teria agido diferente na implantação dessa tecnologia no passado, seja na escolha do produto tecnológico seja na forma de implementação junto aos colaboradores? 
X. Qual a dica você daria para os novos empresários que estão abrindo agora a sua empresa e estão na dúvida de qual software implementar e se vale a pena e/ou compensa o investimento alto em tecnologia em seu negócio?

\subsection{Tratamento e Análises dos dados}

Os dados coletados foram tratados através de uma análise minuciosa. As entrevistas foram gravadas para posteriormente serem transcritas e analisadas. Além disso, foram separadas por entrevistado, sendo analisadas paralelamente, afim de verificar a diferença e semelhança em suas opniões relacionados a automação. A partir disso, foi traçando um paralelo com a automação pré existente nas empresas com as rotinas e estratégias de inovação dos dias de hoje.

\subsection{Limitações do Método}

A metodologia escolhida para o estudo de caso apresentou algumas dificuldades referidas à coleta e ao tratamento dos dados.

Com relação a coleta, não possuiamos históricos das empresas dos entrevistados, para efeito de confrontos dos dados. Além disso, como os entrevistados trabalhavam em empresas diferentes e com perfis diferentes, tinham pouca experiência de mercado, conflitando com o que é referenciado por Lewin a respeito do contexto social das organizações.

Quanto ao tratamento dos dados, o método escolhido permitia uma abertura maior no questionário. Lewin fala do contexto social da organização e seus impactos abrindo margem para respostas genéricas e muitas vezes inconclusívas, o que pode interferir no resultado final. 


\section{Apresentação e Análise de Resultados}

\subsection{Sobre o caso Empresa $X$}

Conforme mencionado no capítulo introdutório, foi conduzido um estudo prático com a empresa $X$ do ramo de Pet Shop, enquadrada no segmento de empresa de pequeno porte, segundo critérios da Lei Complementar 123/2006, com faturamento anual aproximado de $R \$ 420$ mil reais, com o objetivo de comprovar a importância da utilização de ferramentas de automação na gestão de pequenas empresas. A pesquisa visa, após realizar uma síntese sobre a empresa $\mathrm{X}$, comprovar com apoio teórico e com base em entrevistas, como é primordial o controle das atividades diárias através de uma ferramenta de Gestão. Dessa forma, mostrar ainda a importância do incentivo da automação nas microempresas.

A seguir, uma breve descrição da empresa e seus processos internos, falamos ainda um pouco do setor de Pet Shop do Rio de Janeiro e projeções para os próximos anos, para assim mostrar o processo de implementação de um software de gestão operacional na empresa $X$ e a perspectiva após essa implementação nos próximos anos.

A abertura da empresa $X$ aconteceu em Janeiro de 2010, empresa que tinha como missão atuar no mercado de Pet Shop, com a ideia de proporcionar aos animais conforto e atendimento personalizado e principalmente gerar satisfação aos seus donos. E como visão, ser referência no setor de Pet Shops e cuidados com animais na Tijuca, baseado principalmente na projeção de crescimento do setor nos anos seguintes. Desde 2005 o crescimento do mercado de Pet Shop tem aumentado em média 17\% ao ano, segundo dados da revista Exame 2014. "Em 2014, o Brasil tornou se o $2^{\circ}$ maior do Mundo em população total de aves canoras e ornamentais, além de cães e gatos, além de ser o $2^{\circ}$ maior mercado de itens de pet. São mais de 50 milhões de cães e gatos, a segunda maior população do tipo no mundo. De acordo com dados da Associação Brasileira da Indústria de Produtos para Animais de Estimação (Abinpet), o setor faturou 15,2 bilhões de reais em 2013, um crescimento de $7,3 \%$ em relação a 2012. Alimentação ainda responde por mais da metade do 
faturamento, mas a área que mais cresce é a de serviços, com 19\% do mercado e avanço de $26 \%$ entre 2012 e 2013." (Exame 2014)

O segmento de pet food (alimentação) lidera a lista de atividades que fazem parte deste universo, seguida pelo setor de serviços, cuidados com animais - que vão de equipamentos a acessórios e produtos para higiene. 0 setor veterinário também está entre os que puxam o crescimento deste mercado no país, considerado o segundo maior da indústria pet no mundo, atrás dos Estados Unidos e à frente do Reino Unido, França e Alemanha, dados da revista digital Brasil Econômico 2015.

Pensando em mercado de MPEs, do universo de empresas que atua no segmento, 33,5 mil são de pequenas e médias empresas, isso apenas no varejo de pet shops, segundo dados do Instituto Pet Brasil. Mas não são poucas as que investem na diversificação de produtos e serviços. Diante desse panorama a empresa ainda enxerga um grande potencial de crescimento para os próximos anos mesmo diante da crise no Brasil, apoiado no setor que ainda está em constante crescimento, vide indicadores mostrados, e com o apoio de uma ferramenta de automação projeta principalmente redução de custos para os próximos anos.

Existia uma forte resistencia de implantação de qualquer tecnologia nova na empresa devido a falta de conhecimento e conflitos de interesses entre os sócios, o que certamente era um fator limitante na hora da escolha de uma tecnologia. Com a saida de uma das sócias no inicio de 2014 a empresa começou a alavancar resultados e fechou o ano com o maior faturamento e lucro desde a abertura da empresa, sendo hoje gerida por apenas um sócio. Microempresária de aproximadamente 45 anos, sem formação, porém com forte experiência na área comercial.

Desde Outubro do ano de 2015, a empresa passa por um período financeiro ruim e turbulências operacionais. Foi esse o start necessário, para rever todo o processo e entender onde estava o grande problema para uma empresa que havia feito um ano excelente em 2014. A partir de então, vêm adotando métodos de automatização de processos. O primeiro desses métodos foi a contratação de um serviço de software personalizado, que passou a integrar as três principais frentes da empresa: Estética animal, Clínica e Loja. Durante três meses foi realizado testes com três tipos de softwares, sendo eles $\mathrm{K}, \mathrm{Y}$ e Z.

Nos testes foi utilizada a plataforma básica e grátis de cada software disponível na internet durante o período máximo de um mês para cada sistema e para os quais não foram períodos seguidos e sim com intervalo de tempo. A 
partir de uma pesquisa simples de satisfação da proprietária e junto aos colaboradores que manipulariam o sistema, constatou se que o software $Y$, era o que melhor se encaixava entre as tres opções e foi escolhido então para ser utilizado sobre a forma mais completa e paga do sistema, que gira em torno de uma mensalidade de $R \$ 199,00$ por mês, proporcionando acesso total ao usuário e ainda suporte completo para eventuais duvidas e problemas.

A implementação foi simples e rápida, visto que a microempresária já conhecia a ferramenta, sendo apenas necessário assistir as video aulas apresentadas na internet e recadastrar produtos e serviços existentes em sua empresa. Esta é uma das atividades mais trabalhosas da implantação, mas que especificamente para esse aplicativo foi um dos fatores decisivos de escolha, pelo fato de possuir cadastro por leitor de código de barra.

Abaixo exemplo do Software utilizado no Pet Shop, com a imagens dos serviços e oportunidade de automação e conhecimento :

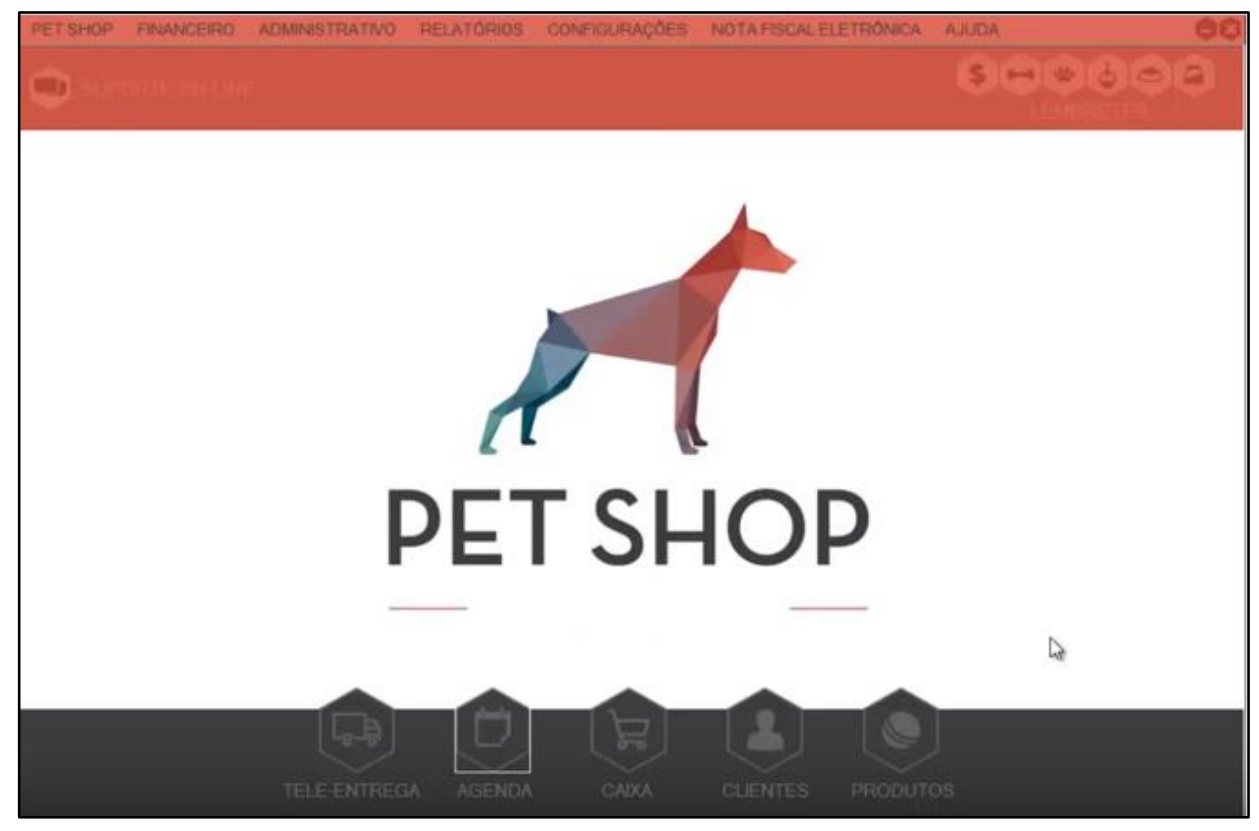

Figura 6 - Software Pet Shop

Fonte: Site da empresa 


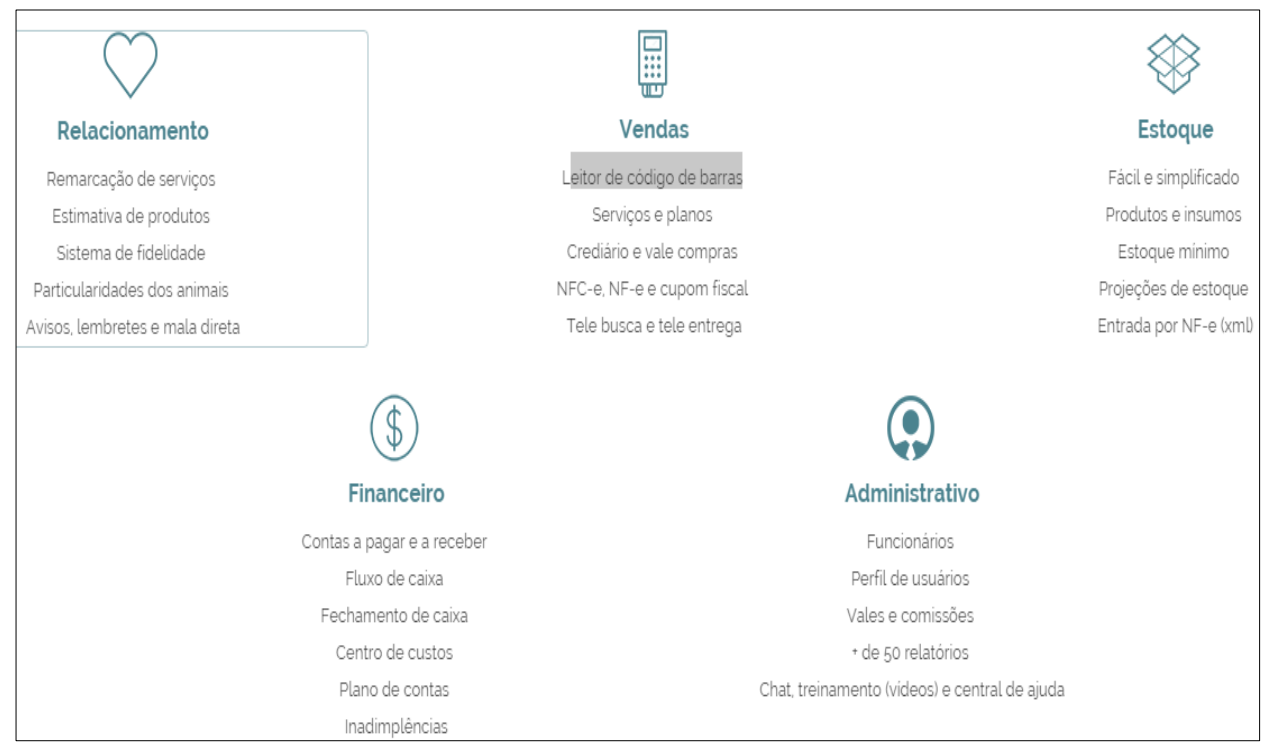

\section{Figura 7 - Funções Software}

Fonte: Site da empresa

Como a empresa não possuia históricos financeiros sólidos e muito menos conseguia identificar onde estava o problema para uma queda tão brusca do faturamento, não estava conseguindo ajustar os erros, passou a ter problemas com clientes, com reclamações de atrasos e desorganização da sua operação, reclamações dos funcionários, pois não estava conseguindo gerir da forma adequada pessoas e ainda teve problemas com a fiscalização. Tudo isso culminou em uma decisão da proprietária em relação a mudança, ou seja, ou mudava ou fechava as portas. A decisão foi de não fechar as portas e apostar na inovação e controle de processos através de estratégias de automação das pequenas empresas, a partir de um suporte de um software que poderá lhe proporcionar ganhos de produtividade significativos, reduzindo o tempo de execução das atividades no curto e longo prazo.

Para efeito de controle, a empresa possuia apenas dados incorporados em um arquivo de excel e nos quais não eram alimentados todos os meses, servindo apenas como uma fonte de consulta esporádica. Abaixo um gráfico comparativo simples, com a informação de lucro de 2015 versus 2014, mês a mês: 


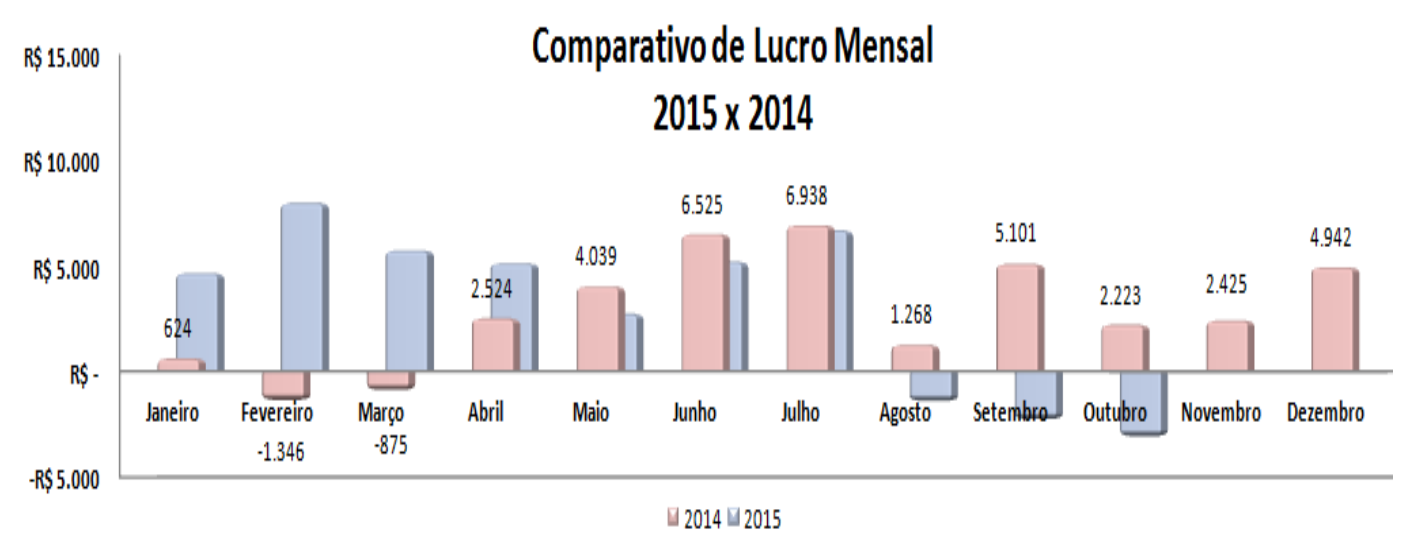

\section{Figura 8 - Gráfico comparativo}

Fonte: Desenvolvido pelo autor

\subsection{Análise dos dados}

Sob forma qualitativa o presente estudo buscou entender como podemos estimular os pequenos e microempresários do Rio de Janeiro a usar ferramentas de automação em seus processos. Para isso foi necessário entender as percepções dos entrevistados em relação as tecnologias existentes no mercado e quais eram seus principais anceios e obstáculos, por eles encontrados, que poderiam estimular ou desestimular a utilização desse fator logistico operacional em seu ambiente de trabalho. A ideia foi gerar recomendações para aumentar o nível de motivação e satisfação com a utilização das ferramentas existentes no mercado e estimular investimento por parte dos microempresários na adoção de tais ferramentas tecnológicas.

Além do estudo de caso apresentado acima, foi realizado também entrevistas com cinco microempresários, feitas a fim de complementar as análises:

Entrevistado 1: Microempresária do ramo de Pet Shop, mulher de aproximadamente 45 anos, mãe, com nível superior incompleto, mas com vasta experiência comercial.

Entrevistado 2: microempresário de 25 anos, cirurgião-dentista, dono de uma clínica na região da Tijuca.

Entrevistado 3: microempresário de 25 anos, sócio-investidor de uma clínica na região da Tijuca. Administrador de empresas e trabalha em uma empresa de Telecom. 
Entrevistado 4: microempresário de 26 anos, sócio-investidor de uma clínica na Tijuca. Administrador de empresas e trabalha em uma empresa do ramo do petróleo.

Entrevistado 5: Empreendedor Individual 27 anos, Engenheiro de Produção e dono de uma microempresa do ramo de alimentos naturais.

Os participantes foram entrevistados separadamente, sendo pedido a cada participante para discutir suas experiências no uso de tecnologias em suas empresas, pensando de um modo macro e micro econômico e levando em consideração resistências pessoais ao uso dessas tecnologias, situações em que essa tecnologia são utilizadas de maneira errada ou até não utilizada e tentou se criar a percepção e entendimento do microempresário do motivo que possa dificultar essa automação por parte deles, mesmo sendo um fator importante para o crescimento tanto das grandes empresas, quanto das pequenas empresas. Vale resssaltar que tivemos uma resistência maior por parte do entrevistado 1 , muito pelo fato de se tratar de um profissional mais experiente e com perfil mais conservador e a respeito de tecnologia, assim como citado pelo entrevistado, a dificuldade de operacionalizar se torna mais evidente e importante fator de bloqueio implemental. Essas barreiras podem ser vencidas através de uma estratégia de implantação gradual e motivacional.

O estudo tem como propósito tentar estimular a implantação de softwares de gestão em seus ambientes de trabalho, através de propostas de ações que pudessem levar a um uso mais eficaz dessa tecnologia. As principais ações sugeridas no estudo e os fatores motivacionais a eles atribuídos aparecem no quadro a seguir. Este quadro foi montado através da percepção das respostas dos entrevistados pelo entrevistador.

Podemos verificar que as ações identificadas frente as soluções tecnológicas consideram, principalmente, aspectos de utilidade e facilidade de uso: 


\begin{tabular}{|c|c|}
\hline Ação & $\begin{array}{c}\text { Fator } \\
\text { Motivacional }\end{array}$ \\
\hline Escolher sistemas amigáveis. & Facilidade Uso / Prazer \\
\hline Importante participação do usuário na implantação da & Utilidade / Facilidade \\
ferramenta. & Uso \\
\hline Realizar treinamento intensivo ao usuário. & Facilidade Uso \\
\hline Facilitar o acesso a todos. & Utilidade \\
\hline O sistema deve responder a todas as suas necessidades. & Utilidade / Prazer \\
\hline Usar uma tecnologia atualizada. & Utilidade \\
\hline Usar tecnologia alinhada ao negócio de sua empresa. & \\
\hline
\end{tabular}

Tabela 2 - Ações para automação bem-sucedida

Fonte: Desenvolvido pelo autor

O presente estudo oferece várias contribuições para o entendimento dos aspectos motivadores e das resistências que os pequenos e microempresários do Rio de Janeiro têm com relação ao uso da tecnologia da informação em seu ambiente de trabalho e na sua rotina operacional e logística.

Além disso, o estudo procurou comprovar a existência e o interrelacionamento de três motivadores citados no quadro acima: utilidade, facilidade de uso e prazer, como os motivos que possam dificultar a automação nas empresas. Todos os entrevistados informaram que utilizam hoje pelo menos uma forma de tecnologia em seu dia a dia, porém foi possível comprovar que o fator motivador como facilidade de uso e prazer são bastante representativos para escolha da tecnologia correta, inclusive podem estar relacionados a idade dos entrevistados e ao conhecimento adquirido por eles no decorrer dos anos sobre a tecnologia e suas funções operacionais.

Com exceção do Entrevistado 1, todos os empresários mostraram unanimidade com relação ao prazer da tecnologia, esse fator motivador mostrou claramente a sua importância. O prazer age como motivador pessoal, enquanto a utilidade é claramente um motivador extra pessoal, ou seja, totalmente relevante. A competitividade com que são realizados os negócios hoje em dia e a ênfase na obtenção de mais eficiência na operação das empresas levam a um cuidado especial com o aspecto da utilidade da tecnologia da informação nas grandes organizações e pensando na mesma lógica, o mesmo racional deveria ser aplicado para as micro e pequenas empresas.

O modelo da pesquisa e o estudo de caso mostrou que quanto mais o empresário cria resistência pessoal à tecnologia, mais difícil ele acha usá-la. Por outro lado, a percepção da utilidade dessa tecnologia é diretamente influenciada 
pelo prazer em usá-la e pela percepção de utilidade e necessidade de uso. Propomos que, se conseguirmos maneiras de diminuir o sentimento inconsciente de rejeição à tecnologia da informação e pudermos gerar mais prazer em seu uso e uma sensação de maior facilidade de uso, esses dois efeitos levaria, certamente, a uma crescente conscientização da utilidade da tecnologia da informação por parte destes microempresários.

A respeito de operação tecnológica os empresários afirmaram que usam tecnologia, principalmente, porque acham que ela aumenta a qualidade do seu trabalho, acelera a execução das tarefas sob a sua responsabilidade e melhora a sua produtividade, porém nenhum dos entrevistados souberam quantificar isso. Ficou claro nas entrevistas que a dificuldade do empreendedor está em identificar as reais necessidades tecnológicas de sua empresa e estabelecer uma intercomunicação sem ruídos através de uma ferramenta, ou seja, a tecnologia pode atrapalhar dependendo de como for implementada. Todos os entrevistados citaram que o fator determinante para o sucesso ou não de implantação de uma ferramenta são os primeiros contatos e que após a adaptação e maior conhecimento sobre as suas funcionalidades fica muito mais fácil estabelecer um pensamento de utilização a longo prazo.

Todos os empresários citaram que utilizam hoje um modelo de software básico, que propõe auxílio para atividades administrativas, operacionais e financeiras básicas. Porém, também citam que a atividade operacional humana permanece ainda indispensável apesar de obterem uma contribuição tecnológica positiva. Consideram como indispensável na hora da escolha e cotação do software, o suporte a todas as atividades operacionais da empresa e usabilidade da ferramenta, além do custo.

O entrevistado 5 afirma que por estar em fase inicial de atividade de sua empresa, e por não possuir um giro muito alto de estoque e pouca complexidade operacional, utiliza apenas a ferramenta Excel para controle de suas operações tanto financeira, quanto diárias. Mas expõe a necessidade de mudança de ferramenta para o aumento muito expressivo de volume e funcionários. $\mathrm{Na}$ mesma linha de raciocínio a entrevistada 1 afirma que devido a implementação estar muito recente, ainda não é possível afirmar se empresa obteve um ganho operacional significativo após a adoção de um software de automação, versus o período anterior.

Fechamos as análises, entendendo a importância da abordagem em relação ao assunto de automação de processos. As microempresas são muito delicadas, dessa forma todo o tipo de revisão de processo impacta 
significamente no modus operandis das organizações, consequentemente pode comprometer todo o funcionamento da cadeia e levar o empresário a estaca inicial. Então, abordando de forma correta, apresentando as soluções operacionais exatas e provando erros na operação logística, conseguimos agregar valor no micronegócio de forma sustentável, gerando autonomia e descentralizando os processos. 


\section{Conclusão e recomendações para novos estudos}

Com base no estudo proposto e nas informações levantadas, foi demonstrado o importante papel dos microempresários no mundo globalizado e a necessidade de mudança na estratégia e cultura das pequenas e microempresas.

O Brasil poderá sofrer um importante impacto em sua economia nos próximos anos e a melhor maneira do microempresário sobreviviver e se preparar para essa crise é conseguindo se estruturar da melhor forma. Isso pode acontecer se forem compreendidos os gaps do seu negócio e os pontos fortes, para através das análises proporcionadas por softwares de automação, se blindar contra efeitos indesejados. A blindagem poderia acontecer na forma de redução de custos ou otimização de processos.

Observando o depoimento dos entrevistados desse estudo, se percebe que todos os negócios abordados já possuem um determinado histórico de vida. São microempresas que já estão em funcionamento constante e que identificam a automação como melhoria diante do cenário do funcionamento da atividade economica existente. Para a execução das atividades empresariais, são exigidos alguns controles básicos e que hoje já existem e acontecem de alguma forma. Essa passa a ser a origem de muitos impecílios para a introdução de um sistema tecnológico, pois quando o negócio já possui um fluxo de atividade que atende as necessidades, já se cria uma barreira na mudança. Além disso, o volume de trabalho para o desenvolvimento e aplicação de uma ferramenta demanda um trabalho extra, além da rotina diária usual que normalmente já é, segundo os entrevistados, em demasia.

Dessa forma, se torna possível fazer recomendações para novos microempresários que permeiam novos investimentos no ramo, no sentido de tangibilizar com maior precisão o potencial do negócio que está sendo iniciado para já planejar uma ferramenta de automação que possa atender grande parte das expectativas do negócio. Adaptações do sitema serão necessárias, como qualquer outro processo que precisa se adaptar ao crescimento. A importância está em já começar o negócio com o sistema em andamento. Incluir esse 
investimento no começo do plano de negócios gera maior aceitação do microempresário, o que torna o processo menos moroso e difícil.

Os benefícios que podem ser considerados caso essa medida seja tomada é o histórico coorporativo já estar todo inserido sem gerar retrabalho caso fosse realizado no futuro. Maior controle sobre indicadores e informações também são benéficos para a saúde do negócio. Além disso, o desenvolvimento do negócio se torna direcionado para a parte analítica das informações e não na parte operacional.

Como recomendações para novos estudos sobre o tema, se destaca o cálculo para mensurar o ganho real da utilização de softwares de gestão, levando todas as variáveis aqui citadas em consideração. Uma maneira em que isso poderia ser feito seria através da realização de coletas de dados logísticos e financeiros de microempresas no Rio de Janeiro que poderiam alcançar um numero percentual e financeiro médio de ganho real com a adoção da automação pelas empresas. Um princípio básico para esse cálculo seria mostrando o comparativo de redução de custos versus ganho na escala operacional. Outras variáveis e análises também poderiam ser exploradas como proporção de ganho de controle versus satisfação do cliente.

Este trabalho provou que a ação de inovar e automatizar, são processos que devem estar intrínssecos no pequeno empresário, mas devem ser tratadas de forma cautelosa e alinhadas com a necessidade da empresa e do mercado. Esse aspecto tecnológico poderia ser ressaltado como um diferencial no cenário do mercado atual. 


\section{Referências Bibliográficas}

BACHMANN, D. L.; DESTEFANI, J. H. Metodologia para estimar o grau de inovação nas MPEs. XVIII Seminário Nacional de Parques Tecnológicos e Incubadoras de Empresas.

Aracaju, 2008.

BALLOU, Ronald H. Gerenciamento da cadeia de suprimentos: logística empresarial. 5. ed.

Porto Alegre: Bookman, 2005

BEDÊ, Marco Aurélio. A informatização nas MPEs Paulistas

São Paulo: SEBRAE, 2003

CHIAVENATO, Idalberto. Introdução à teoria geral da administração

Rio de Janeiro: Campus, 2003

DA SILVA, M. Cristina F.. Inovação e sustentabilidade, bases para o futuro dos pequenos negócio.

São Paulo: SEBRAE, 2013

DRUCKER, Peter Ferdinand. O melhor de Peter Drucker: a administração

São Paulo: Nobel, 2001

Hall, J. Curtis; EDWIN, M. Robinson. Organização e administração de negócios.

Brochura: Mcgraw-Hill, 1971

JONASH, R. S. O valor da inovação: como as empresas mais avançadas atingem alto desempenho e lucratividade.

Rio de janeiro: Campus, 2001. 
KURT, Lewin. Principios de psicologia topológica

São Paulo: Cultrix, 2001

S. A. (Org.). Capacitação tecnológica e competitividade: o desafio para a empresa brasileira.

Curitiba: IEL/PR, 2002.

TACHIZAWA, Takeshy; SCAICO, Oswaldo. Organização flexível.

SÃO PAULO: Atlas, 1997. 331 pp

VERGARA, Sylvia Constant. Projetos e Relatórios de Pesquisa em Administração.

São Paulo: Atlas S.A, 1998.

Sites:

<http://www.sebrae.com.br> Visitado em: 14 Setembro 2015.

<http://www.exame.abril. com.br> Visitado em: 15 Setembro 2015.

<http://www.tudosobrepetshop.com.br> Visitado em: 15 Setembro 2015.

<www.petbr.com.br/cons13.asp $>$ Visitado em: 15 Setembro 2015

$<$ http://www.administradores.com.br/artigos/carreira/conceitos-basicos-domrp-material-requirement-planning/26507/> Visitado em: 15 Setembro 2015 